\title{
Hypothermia and operative mortality during on-pump coronary artery bypass grafting
}

\author{
Kevin L. Greason, MD, ${ }^{a}$ Sunghee Kim, ${ }^{\mathrm{b}}$ Rakesh M. Suri, MD, ${ }^{\mathrm{a}}$ Amelia S. Wallace, BSPH, ${ }^{\mathrm{b}}$ and \\ Brian R. Englum, MD
}

Objective: Controversy surrounds the effect of hypothermia on operative mortality during cardiac surgery. The present study accessed a large clinical database of coronary artery bypass graft operations to address the issue.

\begin{abstract}
Methods: A retrospective review of the Society of Thoracic Surgeons Adult Cardiac Surgery Database identified patients treated with isolated, nonemergency, on-pump coronary artery bypass grafting from July 2011 to December 2012. The patients were divided into 3 groups according to their lowest core temperature during the procedure: moderate hypothermia $\left(\leq 34^{\circ} \mathrm{C}\right)$, mild hypothermia $\left(>34^{\circ} \mathrm{C}\right.$ but $\left.\leq 36^{\circ} \mathrm{C}\right)$, and normothermia $\left(>36^{\circ} \mathrm{C}\right)$. The primary endpoint of the study was operative mortality, defined according to the Database criteria.
\end{abstract}

Results: During the study period, 142,541 patients were available for analysis; $94,777(66.5 \%)$ received moderate hypothermia, 42,750 (30.3\%) mild hypothermia, and 5014 (3.5\%) normothermia. Operative mortality occurred in 1394 patients $(1.5 \%)$ in the moderate hypothermia, $534(1.3 \%)$ in the mild hypothermia, and 105 $(2.1 \%)$ in the normothermia group. Multivariate analysis identified hypothermia (both mild [odds ratio, 0.66; 95\% confidence interval, $0.54-0.81 ; P<.0001$ ] and moderate [odds ratio, $0.73 ; 95 \%$ confidence interval, $0.60-0.89 ; P=.0015]$ ) was protective against operative mortality compared with normothermia. No incremental benefit was noted between the different hypothermia grades $(P=.0827)$.

Conclusions: Most patients receive hypothermia during on-pump coronary artery bypass grafting. Hypothermia is protective against operative mortality compared with normothermia in such patients. Moderate hypothermia does not provide additional survival benefit. (J Thorac Cardiovasc Surg 2014;148:2712-8)

See related commentary on pages $2718-9$.

Controversy exists about the risks and benefits of hypothermia during cardiac surgery. ${ }^{1,2}$ Ho and $\operatorname{Tan}^{3}$ reviewed the effect of hypothermia on cardiac operative mortality in a 2009 meta-analysis and identified 37 reports totaling 6444 patients. The general conclusion was that normothermia during cardiopulmonary bypass in adult cardiac surgery was as safe as that of hypothermia. Importantly, in that meta-analysis, more than one half of the studies contained $<100$ patients and therefore lacked an adequate sample size to address the issue. The Society of Thoracic Surgeons (STS) Adult Cardiac Surgery Database (STS-ACSD) began collecting lowest core

From the Division of Cardiovascular Surgery, ${ }^{\text {a }}$ Mayo Clinic, Rochester, Minn; and Duke Clinical Research Institute, ${ }^{\mathrm{b}}$ Durham, NC.

The present data review was funded by the Society of Thoracic Surgeons.

Disclosures: Rakesh Suri reports being a PI for the Sorin Percival Trial and co-PI of the Abbott CoApt trial. He also reports patent applications form the Sorin Percival Trial, and grant support from Sorin, Edwards, and St. Jude. All other authors have nothing to disclose with regard to commercial support.

Received for publication Jan 6, 2014; revisions received May 12, 2014; accepted for publication May 23, 2014; available ahead of print Aug 12, 2014.

Address for reprints: Kevin L. Greason, MD, Division of Cardiovascular Surgery, Mayo Clinic, 200 First St SW, Rochester, MN 55905 (E-mail: greason.kevin@ mayo.edu).

$0022-5223 / \$ 36.00$

Copyright (C) 2014 by The American Association for Thoracic Surgery

http://dx.doi.org/10.1016/j.jtcvs.2014.05.091 temperature data during the procedure in July 2011. The addition of this field to the database has offered an opportunity to study the effect of hypothermia on operative mortality during cardiac surgery in a large patient population.

\section{METHODS}

The Duke University Health System institutional review board declared this research exempt from review owing to the de-identified nature of the STS-ACSD. Funding limitations allowed analysis of only on-pump coronary artery bypass grafting (CABG). The STS-ACSD was reviewed for all patients treated with isolated CABG from July 1, 2011 to December 31, 2012. Of the 216,321 patients identified, 73,780 patients $(34.1 \%)$ were excluded to develop a more homogenous cohort of stable, nonemergency patients for evaluation (Figure 1). No exclusion criteria were used at the hospital level; however, some hospitals were excluded from the analysis on the basis of the applied patient exclusion criteria.

The patients were divided into 3 groups according to the lowest core temperature during the procedure (STS-ACSD, version 2.73, sequence no. 2780): moderate hypothermia $\left(\leq 34^{\circ} \mathrm{C}\right)$, mild hypothermia $\left(>34^{\circ} \mathrm{C}\right.$ and $\left.\leq 36^{\circ} \mathrm{C}\right)$, or normothermia $\left(>36^{\circ} \mathrm{C}\right)$. The distinction between mild and moderate hypothermia was determined by institutional practice. The patient characteristics studied were the standard STS risk model covariates (ie, risk calculator variables) and additional non-risk model covariates (Table 1), which also included the hospital CABG volume. ${ }^{4}$

The primary endpoint of the present study was operative mortality, which was defined as operative death (sequence no. 6390), discharge death (no. 6370), or death at 30 days after surgery (no. 6380). The secondary individual endpoints were permanent stoke (no. 6030) and reoperation for bleeding or tamponade (no. 5760). A combined infection endpoint was also used and consisted of the individual endpoints of deep sternal 


\section{Abbreviations and Acronyms \\ $\mathrm{CABG}=$ coronary artery bypass grafting \\ $\mathrm{CI}=$ confidence interval \\ OR $\quad=$ odds ratio \\ STS $\quad=$ Society of Thoracic Surgeons \\ STS-ACSD $=$ Society of Thoracic Surgeons Adult \\ Cardiac Surgery Database}

infection (no. 5860), mediastinitis (no. 5870), pneumonia (no. 6150), and sepsis (no. 6010).

Descriptive statistics for categorical variables are reported as counts and percentages and continuous variables as the mean \pm standard deviation and/or median and interquartile range. Categorical variables were compared using the chi-square test and continuous variables using the Kruskal-Wallis test.

Univariate and multivariate associations between the 4 endpoints and the 3 perfusion temperature groups were assessed using logistic regression analysis with the generalized estimating equation. To compare mild or moderate hypothermia with normothermia on each outcome, multivariate models were adjusted for the STS risk model covariates and non-risk model covariates, in addition to the 3 perfusion temperature groups. Missing covariates were imputed using most common category for categorical covariates and group-specific medians for continuous covariates. All continuous covariates were tested for linearity, and nonlinear relationships were accounted for using flexible splines, including linear splines or quadratic polynomial. All statistical tests were 2-sided, with the $\alpha$ level set at 0.05 for statistical significance. All analyses were performed using SAS, version 9.3 (SAS Institute, Cary, NC).

\section{RESULTS}

The study group included 142,541 patients treated with on-pump, nonemergency, isolated CABG. During cardiopulmonary bypass, 94,777 patients $(66.5 \%)$ received moderate hypothermia, 42,750 (30.0\%) mild hypothermia, and $5014(3.5 \%)$ normothermia. A histogram of the lowest core temperature of the study group during the procedure is shown in Figure 2. The STS patient risk model covariates are listed as patient characteristics in Table 2. The operative data are reported in Table 3.

Operative mortality occurred in 1394 patients $(1.5 \%)$ in the moderate hypothermia group, $534(1.3 \%)$ in the mild hypothermia group, and $105(2.1 \%)$ in the normothermia group. Stroke occurred in 1257 patients $(1.3 \%)$ in the moderate group, $495(1.2 \%)$ in the mild group, and 57 $(1.1 \%)$ in the normothermia group. Reoperation occurred in $1662(1.8 \%)$ in the moderate group, $716(1.7 \%)$ in the mild group, and $99(2.0 \%)$ in the normothermia group $(P=.025)$. Finally, infection occurred in $3189(3.4 \%)$ in the moderate group, $1318(3.1 \%)$ in the mild group, and $161(3.2 \%)$ in the normothermia group.

Univariate analysis identified mild hypothermia to be protective against operative mortality compared with normothermia (odds ratio [OR], $0.60 ; 95 \%$ confidence interval $[\mathrm{CI}], 0.49-0.72 ; P<.0001)$ and moderate

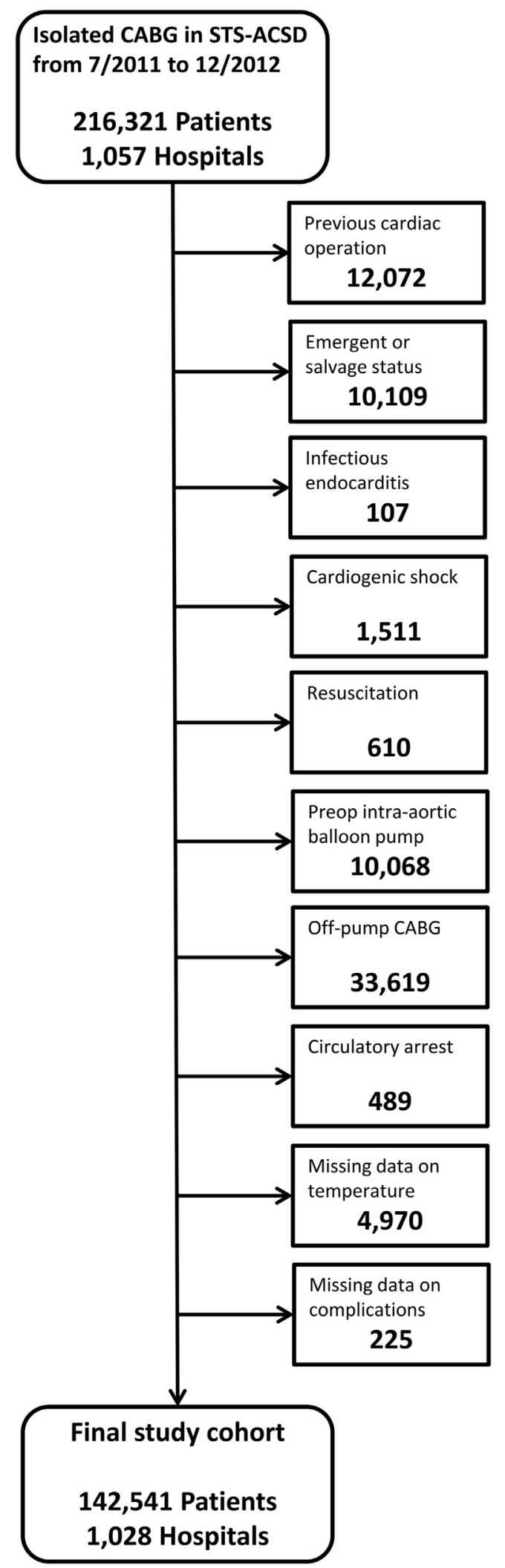

FIGURE 1. Algorithm describing patient exclusion process. $C A B G$, Coronary artery bypass grafting; STS-ACSD, Society of Thoracic Surgeons Adult Cardiac Surgery Database. 
TABLE 1. Society of Thoracic Surgeons non-risk model covariates

Age by group: $<55,55-64,65-74$, and $\geq 75$ y (STS-ACSD no. 140)

History of smoking (STS-ACSD nos. 650 and 661)

No. of distal anastomoses with venous conduit (STS-ACSD no. 3200)

No. of distal anastomoses with arterial conduit (STS-ACSD no. 3190)

Dyslipidemia (STS-ACSD no. 800)

Radial arterial used for grafts (STS-ACSD no. 3260)

Preoperative medication, $\beta$-blocker (STS-ACSD no. 1710)

Preoperative medication, ACE inhibitor or ARB within 48 h (STS-ACSD no. 1730)

Preoperative medication, anticoagulant (STS-ACSD nos. 1750, 1780, $1850,1880,1900)$

Preoperative medication, aspirin (STS-ACSD no. 1820)

Preoperative medication, lipid lowering (STS-ACSD no. 1830)

Proper antibiotic administration (STS-ACSD nos. 2710 and 2720)

$S T S-A C S D$, Society Thoracic Surgeons Adult Cardiac Surgery Database, version 2.73; $A C E$, angiotensin-converting enzyme; $A R B$, angiotensin II receptor blocker.

hypothermia (OR, 0.86; 95\% CI, 0.77-0.95; $P=.0028$ ). Furthermore, mild hypothermia was protective against stroke compared with moderate hypothermia (OR, 0.87; 95\% CI, 0.77-0.97; $P=.0125)$. Moderate hypothermia was protective against operative mortality compared with normothermia (OR, $0.70 ; 95 \% \mathrm{CI}, 0.58-0.84 ; P=.0002)$. Additional univariate analyses of perfusion temperature and endpoints are reported in Table 4.

Multivariate analysis identified mild hypothermia was protective against operative mortality compared with normothermia (OR, 0.66; 95\% CI, 0.54-0.81; $P<.0001$ ). Moderate hypothermia was also protective against mortality compared with normothermia (OR, 0.73; 95\% CI, 0.60-0.89; $P=.0015$ ). Mild hypothermia was not significantly protective against operative mortality compared with moderate hypothermia $(P=.0827)$. No other perfusion temperature-related variables were protective of the primary or secondary endpoints (Table 5).

\section{DISCUSSION}

The effect of hypothermia during cardiac surgery is controversial, and current data have provided conflicting guidance. With a small anticipated effect size, most studies have lacked an adequate sample size to evaluate the question. The present study leveraged the large patient volume in the STS-ACSD to evaluate the effect of hypothermia in patients undergoing on-pump CABG. In a group of 142,541 patients, $96.5 \%$ of the patients received hypothermia $\left(\leq 36^{\circ} \mathrm{C}\right)$, which was protective against mortality compared with normothermia. This held true in multivariate analysis of both mild hypothermia $\left(>34^{\circ} \mathrm{C}\right.$ and $\leq 36^{\circ} \mathrm{C}$; OR, 0.66 ; 95\% CI, 0.54-0.81; $\left.P<.0001\right)$ and moderate hypothermia $\left(\leq 34^{\circ} \mathrm{C} ; \mathrm{OR}, 0.73 ; 95 \% \mathrm{CI}\right.$, $0.60-0.89 ; P=.0015$ ). No benefit was seen for operative mortality, however, in the comparison of mild and moderate hypothermia $(P=.0827)$.

An attempt was made to create study cohorts that were as homogeneous as possible. In doing so, 73,780 patients $(34.1 \%)$ and 29 hospitals $(2.7 \%)$ were excluded from the present study. These are significant numbers; however, the covariates used to exclude the patients and hospitals were clearly variables that would have confounded our analysis. Most are known to be clinically significant predictors of operative mortality, and, hence, their presence could have contaminated the outcome analysis. Examples of such variables include reoperation (operative mortality, OR, 3.13), shock (OR, 2.9), and emergency status with resuscitation or salvage (OR, 8.00). ${ }^{4}$ Exclusion of these types of patients from the analysis seemed reasonable and still left a study group of $>142,000$ patients.

An important issue to consider is what constitutes normothermia. Mackowiak and colleagues ${ }^{5}$ studied 700 temperature recordings from 148 healthy patients. They reported a mean temperature of $36.8^{\circ} \mathrm{C} \pm 0.4^{\circ} \mathrm{C}$. Thus,

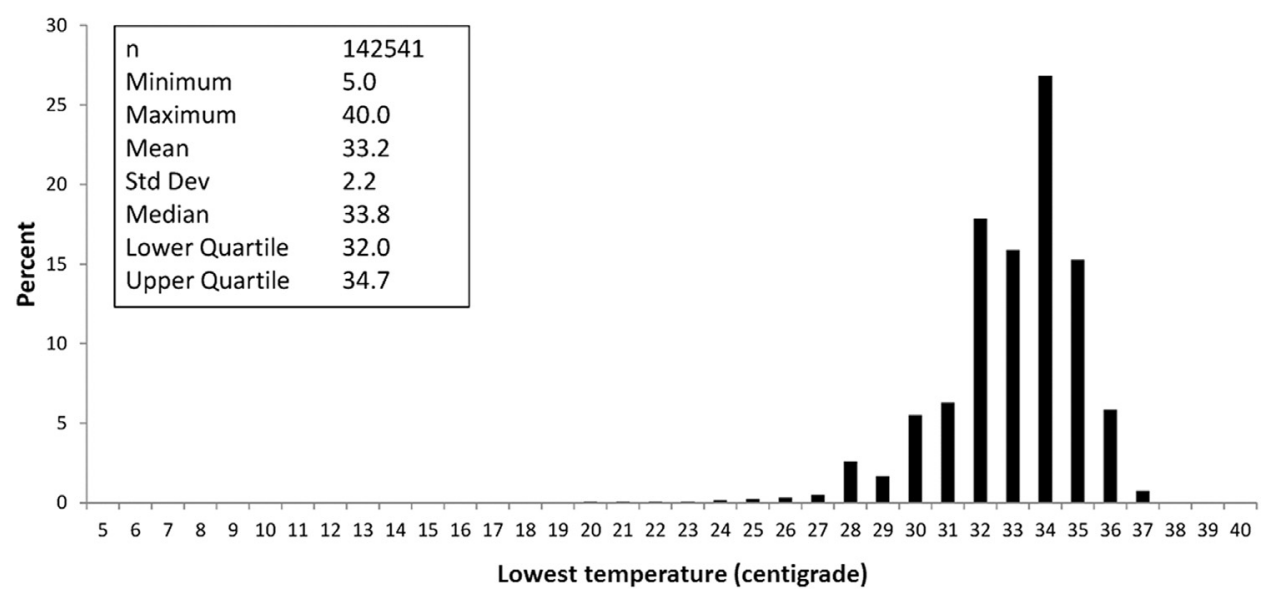

FIGURE 2. Histogram of lowest patient temperature during on-pump coronary artery bypass grafting for the entire study group ( $\mathrm{n}=142,541$ patients). Std Dev, Standard deviation. 
TABLE 2. Society of Thoracic Surgeons risk model covariates according to lowest core temperature during the procedure

\begin{tabular}{|c|c|c|c|c|}
\hline Variable & $\begin{array}{l}\text { Moderate hypothermia } \\
(\mathrm{n}=\mathbf{9 4 , 7 7 7}) \\
\end{array}$ & $\begin{array}{l}\text { Mild hypothermia } \\
\quad(\mathrm{n}=\mathbf{4 2 , 7 5 0 )}\end{array}$ & $\begin{array}{c}\text { Normothermia } \\
(\mathbf{n}=\mathbf{5 0 1 4})\end{array}$ & $P$ value \\
\hline \multicolumn{5}{|l|}{ Continuous variables } \\
\hline Age (y) & & & & $<.0001$ \\
\hline Mean \pm SD & $65.1 \pm 10.3$ & $64.3 \pm 10.4$ & $63.7 \pm 10.7$ & \\
\hline Median (IQR) & $65(58-73)$ & $65(57-72)$ & $64(56-71)$ & \\
\hline $\operatorname{BSA}\left(\mathrm{m}^{2}\right)$ & & & & $<.0001$ \\
\hline Mean \pm SD & $2.00 \pm 0.24$ & $2.03 \pm 0.25$ & $2.05 \pm 0.25$ & \\
\hline Median (IQR) & $2.00(1.84-2.16)$ & $2.03(1.87-2.19)$ & $2.05(1.87-2.21)$ & \\
\hline Last preoperative creatinine $(\mathrm{mg} / \mathrm{dL})$ & & & & .0150 \\
\hline Mean \pm SD & $1.17 \pm 0.99$ & $1.16 \pm 0.98$ & $1.16 \pm 0.94$ & \\
\hline Median (IQR) & $1.0(0.80-1.2)$ & $1.00(0.80-1.20)$ & $1.00(0.80-1.20)$ & \\
\hline Ejection fraction $(\%)$ & & & & $<.0001$ \\
\hline Mean \pm SD & $52.5 \pm 12.1$ & $52.5 \pm 11.9$ & $51.0 \pm 12.9$ & \\
\hline Median (IQR) & $55(45-60)$ & $55(45-60)$ & $55(44-60)$ & \\
\hline \multicolumn{5}{|l|}{ Categorical variables } \\
\hline Female sex & $24,887(26.26)$ & $10,443(24.43)$ & $1252(24.97)$ & $<.0001$ \\
\hline White race & $76,777(81.01)$ & $35,665(83.43)$ & $4237(84.50)$ & $<.0001$ \\
\hline Smoking history* & $31,803(33.56)$ & $14,284(33.41)$ & $1666(33.23)$ & .8332 \\
\hline Diabetes & & & & .0065 \\
\hline Insulin treated & $15,360(16.21)$ & $6807(15.92)$ & $873(17.41)$ & \\
\hline Non-insulin treated & $27,595(29.12)$ & $12,504(29.25)$ & $1518(30.28)$ & \\
\hline Dialysis & $2521(2.66)$ & $1093(2.56)$ & $136(2.71)$ & .4932 \\
\hline Hypertension & $83,198(87.78)$ & $37,497(87.71)$ & $4418(88.11)$ & .7012 \\
\hline Chronic lung disease & & & & $<.0001$ \\
\hline Moderate & $5803(6.12)$ & $2590(6.06)$ & $346(6.90)$ & \\
\hline Severe & $3900(4.11)$ & $1814(4.24)$ & $251(5.01)$ & \\
\hline Immunosuppression & $2304(2.43)$ & $1011(2.36)$ & $139(2.77)$ & .1995 \\
\hline PVD & $13,283(14.02)$ & $5658(13.24)$ & $672(13.40)$ & .0003 \\
\hline CVD & & & & .0005 \\
\hline Stroke & $6778(7.15)$ & $2821(6.60)$ & $334(6.66)$ & \\
\hline No stroke & $6702(7.07)$ & $2906(6.80)$ & $337(6.72)$ & \\
\hline Previous PCI & $23,660(93.78)$ & $11,216(94.05)$ & $1361(94.32)$ & .4388 \\
\hline Myocardial infarction & & & & $<.0001$ \\
\hline$<24 \mathrm{~h}$ & $1269(1.34)$ & $588(1.38)$ & $135(2.69)$ & \\
\hline $1-21 \mathrm{~d}$ & $25,947(27.38)$ & $11,320(26.48)$ & $1569(31.29)$ & \\
\hline$>21 \mathrm{~d}$ & $17,435(18.40)$ & $7913(18.51)$ & $846(16.87)$ & \\
\hline Unstable angina & $35,224(37.17)$ & $16,375(38.30)$ & $1924(38.37)$ & .0001 \\
\hline NYHA functional classification & & & & $<.0001$ \\
\hline Class I-III & $11,324(11.95)$ & 4698 (10.99) & $629(12.54)$ & \\
\hline Class IV & $2817(2.97)$ & $1172(2.74)$ & $190(3.79)$ & \\
\hline Atrial fibrillation/flutter & $5820(6.14)$ & $2508(5.87)$ & $360(7.18)$ & .0008 \\
\hline Inotropes & $578(0.61)$ & $244(0.57)$ & $36(0.72)$ & .3833 \\
\hline No. of diseased coronary vessels & & & & $<.0001$ \\
\hline 2 & $16,281(17.18)$ & $9627(22.52)$ & $1133(22.60)$ & \\
\hline 3 & $76,590(80.81)$ & $31,058(72.65)$ & $3508(69.96)$ & \\
\hline Left main disease $>50 \%$ stenosis & $29,757(31.40)$ & $13,219(30.92)$ & $1523(30.37)$ & .0948 \\
\hline Aortic valve stenosis & $2121(2.24)$ & $1005(2.35)$ & $105(2.09)$ & .3137 \\
\hline Mitral valve stenosis & $249(0.26)$ & $117(0.27)$ & $15(0.30)$ & .8631 \\
\hline Aortic valve regurgitation, moderate plus & $956(1.01)$ & $443(1.04)$ & $49(0.98)$ & .8711 \\
\hline Mitral valve regurgitation, moderate plus & $4250(4.48)$ & $1854(4.34)$ & $261(5.21)$ & .0193 \\
\hline Tricuspid valve regurgitation, moderate plus & $1790(1.89)$ & $885(2.07)$ & $128(2.55)$ & .0011 \\
\hline Status, urgent & $54,559(57.57)$ & $24,424(57.13)$ & $3156(62.94)$ & $<.0001$ \\
\hline
\end{tabular}


TABLE 3. Operative characteristics

\begin{tabular}{|c|c|c|c|c|}
\hline Variable & $\begin{array}{l}\text { Moderate hypothermia } \\
\quad(n=94,777)\end{array}$ & $\begin{array}{l}\text { Mild hypothermia } \\
\quad(n=42,750)\end{array}$ & $\begin{array}{l}\text { Normothermia } \\
\quad(\mathbf{n}=\mathbf{5 0 1 4})\end{array}$ & $P$ value \\
\hline \multicolumn{5}{|l|}{ Continuous variables } \\
\hline \multicolumn{5}{|c|}{ Blood products transfused intraoperatively (U) } \\
\hline PRBCs & & & & $<.0001$ \\
\hline Mean \pm SD & $1.81 \pm 1.58$ & $1.72 \pm 1.61$ & $1.82 \pm 1.73$ & \\
\hline Median (IQR) & $2(1-2)$ & $2(1-2)$ & $2(1-2)$ & \\
\hline FFP & & & & .0040 \\
\hline Mean \pm SD & $0.63 \pm 1.25$ & $0.64 \pm 1.26$ & $0.66 \pm 1.25$ & \\
\hline Median (IQR) & $0(0-1)$ & $0(0-0)$ & $0(0-1)$ & \\
\hline Platelets & & & & .0618 \\
\hline Mean \pm SD & $1.01 \pm 2.36$ & $1.07 \pm 2.44$ & $0.93 \pm 1.86$ & \\
\hline Median (IQR) & $0(0-1)$ & $0(0-1)$ & $0(0-1)$ & \\
\hline Cryoprecipitate & & & & $<.0001$ \\
\hline Mean \pm SD & $0.15 \pm 1.06$ & $0.31 \pm 1.81$ & $0.22 \pm 1.27$ & \\
\hline Median (IQR) & $0(0-0)$ & $0(0-0)$ & $0(0-0)$ & \\
\hline \multicolumn{5}{|c|}{ Blood products transfused postoperatively (U) } \\
\hline PRBCs & & & & .7006 \\
\hline Mean \pm SD & $2.34 \pm 2.33$ & $2.34 \pm 2.42$ & $2.38 \pm 2.28$ & \\
\hline Median (IQR) & $2(1-3)$ & $2(1-3)$ & $2(1-3)$ & \\
\hline FFP & & & & .0001 \\
\hline Mean \pm SD & $0.59 \pm 1.64$ & $0.55 \pm 1.61$ & $0.55 \pm 1.44$ & \\
\hline Median (IQR) & $0(0-0)$ & $0(0-0)$ & $0(0-0)$ & \\
\hline Platelets & & & & .2295 \\
\hline Mean \pm SD & $0.52 \pm 1.78$ & $0.46 \pm 1.68$ & $0.48 \pm 1.79$ & \\
\hline Median (IQR) & $0(0-0)$ & $0(0-0)$ & $0(0-0)$ & \\
\hline Cryoprecipitate & & & & .0014 \\
\hline Mean \pm SD & $0.18 \pm 1.16$ & $0.23 \pm 1.48$ & $0.26 \pm 1.81$ & \\
\hline Median (IQR) & $0(0-0)$ & $0(0-0)$ & $0(0-0)$ & \\
\hline Skin incision time (min) & & & & $<.0001$ \\
\hline Mean \pm SD & $243 \pm 71.6$ & $224 \pm 68.8$ & $216 \pm 74.7$ & \\
\hline Median (IQR) & $235(194-285)$ & $216(177-262)$ & $206(165-258)$ & \\
\hline Total ventilation time (h) & & & & $<.0001$ \\
\hline Mean \pm SD & $17.8 \pm 63.8$ & $15.9 \pm 55.8$ & $17.0 \pm 53.5$ & \\
\hline Median (IQR) & $6.95(4.58-12.30)$ & $6.32(4.25-11.25)$ & $6.33(4.08-12.33)$ & \\
\hline Total ICU time (h) & & & & $<.0001$ \\
\hline Mean \pm SD & $67.5 \pm 94.3$ & $62.1 \pm 85.7$ & $65.0 \pm 110.2$ & \\
\hline Median (IQR) & $46.5(25.0-73.7)$ & $44.0(24.0-71.0)$ & $43.7(23.8-72.0)$ & \\
\hline \multicolumn{5}{|l|}{ Categorical variables } \\
\hline Intraoperative blood transfusion & $33,678(35.53)$ & $12,523(29.29)$ & $1532(30.55)$ & $<.0001$ \\
\hline Postoperative blood transfusion & $36,472(38.48)$ & $14,719(34.43)$ & $1801(35.92)$ & $<.0001$ \\
\hline Readmission to ICU & $2801(2.96)$ & $1160(2.71)$ & $153(3.05)$ & .0395 \\
\hline
\end{tabular}

Data presented as mean $\pm \mathrm{SD}$, median (IQR), or n (\%). PRBCs, Packed red blood cells; $S D$, standard deviation; $I Q R$, interquartile range; $F F P$, fresh frozen plasma; $I C U$, intensive care unit.

$95 \%$ of healthy patients would have a temperature of $36.0^{\circ} \mathrm{C}$ to $37.6^{\circ} \mathrm{C}$, and the lower limit of normothermia would be $36.0^{\circ} \mathrm{C}$, such as was used in the present study. In the meta-analysis of 37 studies by Ho and colleagues, ${ }^{3}$ normothermia was reported to be a temperature of $33.0^{\circ} \mathrm{C}$ to $38.0^{\circ} \mathrm{C}$. Furthermore, hypothermia was variously worded as hypothermia, mild, moderate, moderate-deep, or deep, usually with 1 break point of temperature that ranged from $20.0^{\circ} \mathrm{C}$ to $37.0^{\circ} \mathrm{C}$. The present study adhered to a clear definition of normothermia and has provided a reasonable distinction between the hypothermia levels.
The 3 cohorts in the present study were significantly different in baseline patient characteristics. Many of these factors are known to affect operative mortality. Recognizing this, each of the STS risk model covariates reported in Table 2, in addition to those non-risk model covariates listed in Table 1, was entered into the multivariate analysis of the effect of temperature on the primary and secondary outcomes. A total of 39 clinically relevant patient characteristics were entered into the analysis. Given the large number of patients in the present study and the robust nature of the multivariate analysis, additional statistical 
TABLE 4. Univariate logistic regression analysis of lowest core temperature levels during the procedure and endpoint outcomes

\begin{tabular}{|c|c|c|c|c|c|c|}
\hline \multirow[b]{2}{*}{ Outcome } & \multicolumn{2}{|c|}{ Mild vs normothermia } & \multicolumn{2}{|c|}{ Moderate vs normothermia } & \multicolumn{2}{|c|}{ Mild vs moderate hypothermia } \\
\hline & Unadjusted OR $(95 \% \mathrm{CI})$ & $P$ value & Unadjusted OR $(95 \%$ CI $)$ & $P$ value & Unadjusted OR $(95 \%$ CI $)$ & $P$ value \\
\hline Operative mortality & $0.60(0.49-0.72)$ & $<.0001$ & $0.70(0.58-0.84)$ & .0002 & $0.86(0.77-0.95)$ & .0028 \\
\hline Stroke & $1.03(0.76-1.39)$ & .8645 & $1.19(0.90-1.57)$ & .2307 & $0.87(0.77-0.97)$ & .0125 \\
\hline Infection & $1.02(0.85-1.21)$ & .8680 & $1.09(0.91-1.30)$ & .3634 & $0.93(0.86-1.01)$ & .0818 \\
\hline Reoperation & $0.86(0.69-1.07)$ & .1809 & $0.91(0.73-1.14)$ & .4205 & $0.94(0.85-1.04)$ & .2180 \\
\hline
\end{tabular}

$O R$, Odds ratio; $C I$, confidence interval.

assessment using propensity matching or other methods was thought not to be indicated.

The effect of hypothermia during cardiac surgery has been controversial in the reported studies. Ho and colleagues $^{3}$ thoroughly reviewed the worldwide published data on the topic. In their review of 37 studies, they reported that hypothermia was harmful in 16 studies, not estimable in 13 , and beneficial in 8 . However, more than one half of the studies reported on $<100$ patients. The largest study contained 1732 patients and used a combined endpoint of mortality and nonfatal Q-wave myocardial infraction in its power calculation to determine the sample size. ${ }^{6}$ That study showed no difference in the individual or combined endpoint. The investigators rightly pointed out that hypothermia can reduce the oxygen demand. ${ }^{6}$ It is precisely that which was most likely the source of the association of hypothermia and reduced operative mortality reported in the present study.

The strength of the present study was evident in the large number of subjects in each study group, allowing for vigorous statistical assessment. The importance of this statement can be found in a review of the data reported by Ho and colleagues. ${ }^{3}$ For comparison, a sample size of $>10,189$ patients per group would be required to detect the difference in their reported mortality rates for hypothermia $(1.9 \%)$ versus normothermia $(1.4 \%)$. This is assuming $80 \%$ power under mortality rate assumptions consistent with their findings (test of independent proportions; 2-sided $\alpha=0.05$ ). No other studies have provided such numbers, apart from the present evaluation.

The main limitations of the present study were selection bias, unmeasured confounders, and retrospective data collection. These limitations were most evident in that the patient characteristics were not equally distributed among the study groups. Although multivariate analysis was used with an extensive list of potential confounders, unmeasured variables remained a potential bias. The method of hypothermia grouping was also a concern.

The intent of the present analysis was to address the treatment decision of the degree of hypothermia as broad strategies of moderate, mild, and no hypothermia. Although surgeons often choose an exact temperature goal, the actual temperature achieved will often be determined by a number of other factors about the case (eg, patient size, duration of bypass time). Although a continuous analysis could be used to identify temperature cutpoints, the estimation of such cutpoints could be unreliable and subject to overinterpretation. Finally, a continuous analysis could lead to extreme estimates in the tails of the distribution where the data are sparse.

Funding for our project was limited and prevented additional data analysis and hypothesis testing, with its attendant implications. To be clear, the data and analysis established an association between temperature and operative mortality; however, causality remains speculative. Also of importance was that the minority of patients $(3.5 \%)$ received normothermic perfusion. The reasoning for such a choice remains unknown and certainly could have implications on the measured endpoints. Finally, the findings in our report apply only to select patients treated with isolated, nonemergency, on-pump CABG and should not be generalized to other operative groups (eg, emergency $\mathrm{CABG}$, valve repair or replacement).

\section{CONCLUSIONS}

Most patients in the STS-ACD who underwent on-pump $\mathrm{CABG}$ had a core temperature during the procedure of $\leq 36^{\circ} \mathrm{C}$. Patients who received hypothermia demonstrated a significant mortality benefit compared

TABLE 5. Multivariate logistic regression analysis of lowest core temperature levels during the procedure and endpoint outcomes

\begin{tabular}{|c|c|c|c|c|c|c|}
\hline \multirow[b]{2}{*}{ Outcome } & \multicolumn{2}{|c|}{ Mild vs normothermia } & \multicolumn{2}{|c|}{ Moderate vs normothermia } & \multicolumn{2}{|c|}{ Mild vs moderate hypothermia } \\
\hline & Adjusted OR (95\% CI) & $P$ value & Adjusted OR (95\% CI) & $P$ value & Adjusted OR (95\% CI) & $P$ value \\
\hline Operative mortality & $0.66(0.54-0.81)$ & $<.0001$ & $0.73(0.60-0.89)$ & .0015 & $0.91(0.82-1.01)$ & .0827 \\
\hline Stroke & $1.08(0.80-1.46)$ & .6211 & $1.13(0.85-1.49)$ & .4063 & $0.96(0.85-1.08)$ & .4723 \\
\hline Infection & $1.09(0.91-1.30)$ & .3541 & $1.13(0.94-1.36)$ & .1823 & $0.96(0.89-1.04)$ & .3253 \\
\hline Reoperation & $0.86(0.69-1.08)$ & .2033 & $0.89(0.71-1.11)$ & .2952 & $0.97(0.88-1.07)$ & .6025 \\
\hline
\end{tabular}

$O R$, Odds ratio; $C I$, confidence interval. 
with those who maintained a normal temperature (ie, $>36^{\circ} \mathrm{C}$ ). Greater degrees of hypothermia (ie, $<34^{\circ} \mathrm{C}$ vs $\geq 34^{\circ} \mathrm{C}$ ) did not result in more benefit. The strength of our analysis was the large number of subjects in the database. Additional examination of the data is indicated to better identify the breakpoint temperature at which benefit will be derived.

\section{References}

1. Roman PEF, Grigore AM. Pro: hypothermic cardiopulmonary bypass should be used routinely. J Cardiothorac Vasc Anesth. 2012;26:945-8.
2. Patel PA, Desai ND. Con: cardiac surgery should be performed under warm conditions. J Cardiothorac Vasc Anesth. 2012;26:948-51.

3. Ho KM, Tan JA. Benefits and risks of maintaining normothermia during cardiopulmonary bypass in adult cardiac surgery: a systemic review. Cardiovasc Ther. 2011;4:260-79.

4. Shahian DM, O'Brien SM, Filardo G, Ferraris VA, Haan CK, Rich JB, et al. The Society of Thoracic Surgeons 2008 Cardiac Surgery Risk Models: part 1-coronary artery bypass grafting surgery. Ann Thorac Surg. 2009;88: S2-22.

5. Mackowiak PA, Wasserman SS, Levine MM. A critical appraisal of $98.6^{\circ} \mathrm{F}$, the upper limit of the normal body temperature, and other legacies of Carl Reinhold August Wunderlich. JAMA. 1992;268:1578-90.

6. The Warm Heart Investigators. Randomized trial of normothermia versus hypothermic coronary bypass surgery. Lancet. 1994;343:559-63.

\title{
EDITORIAL COMMENTARY
}

\section{To cool or not to cool?}

\author{
Jennifer S. Lawton, MD
}

See related article on pages $2712-8$.

To cool or not to cool - that is the question that is raised by the recent study by Greason and colleagues ${ }^{1}$ appearing in this issue of the Journal. Greason and colleagues ${ }^{1}$ used the Society of Thoracic Surgeons database to evaluate patients undergoing nonemergency on-pump isolated coronary artery bypass grafting (CABG) with specific attention to the effect of lowest intraoperative recorded core body temperature on the primary end point of operative mortality and secondary end points of stroke, reoperation for bleeding, and a combined infection end point.

The main strength of the study is in the large number of patients included in the analysis $(\mathrm{N}=142,541)$, because previous studies have had too few patients to demonstrate meaningful statistical differences between groups. Patients were categorized into temperature groups according to the lowest recorded intraoperative temperature: moderate hypothermia $\left(\leq 34^{\circ} \mathrm{C} ; \mathrm{N}=94,777\right)$, mild hypothermia $\left(>34^{\circ} \mathrm{C}\right.$ and $\left.\leq 36^{\circ} \mathrm{C} ; \mathrm{N}=42,750\right)$, and normothermia $\left(>36^{\circ} \mathrm{C} ; \mathrm{N}=5014\right)$. The study spanned an 18 -month period.

From the Department of Surgery, Washington University School of Medicine, St Louis, Mo.

Disclosures: Author has nothing to disclose with regard to commercial support.

Received for publication Sept 24, 2014; accepted for publication Sept 25, 2014; available ahead of print Oct 22, 2014.

Address for reprints: Jennifer S. Lawton, MD, Department of Surgery, Washington University School of Medicine, 660 S Euclid Ave, Campus Box 8234, St Louis, MO 63110 (E-mail: lawtonj@wustl.edu).

J Thorac Cardiovasc Surg 2014;148:2718-9

$0022-5223 / \$ 36.00$

Copyright (c) 2014 by The American Association for Thoracic Surgery

http://dx.doi.org/10.1016/j.jtcvs.2014.09.090
Univariate analysis demonstrated that mild hypothermia was better than moderate hypothermia which in turn was better than normothermia for the end point of operative mortality; however, operative mortality was $1.5 \%$ in the moderate hypothermia group, $1.3 \%$ in the mild hypothermia group, and $2.1 \%$ in the normothermia group. After multivariate analysis, mild and moderate hypothermia were protective relative to normothermia for the primary end point of operative mortality; however, mild hypothermia was not protective relative to moderate hypothermia.

Unfortunately, this large study was retrospective in nature and involved very different populations and enrollment biases. Clearly, the normothermic group was the sickest of all groups; it had more patients with lower ejection fraction, diabetes mellitus, chronic lung disease, recent myocardial infarction, unstable angina, higher New York Heart Association classification, atrial fibrillation or flutter, and urgent status. The normothermic patient group also had a higher incidence of readmission to the intensive care unit. In addition, Greason and colleagues ${ }^{1}$ excluded patients with known predictors of operative mortality $(\mathrm{N}=73,780)$, including reoperation, shock, emergency status with resuscitation, or salvage, to "create study cohorts that were as homogeneous as possible." This may have introduced additional bias, despite multivariate adjustment attempts.

Do the results of this study indicate that hypothermia is good, hyperthermia is bad, or both? Greason and colleagues $^{1}$ speculated that hypothermia is protective as a result of reduced oxygen demand during $\mathrm{CABG}$; however, does this really affect operative mortality? Hypothermia may also be detrimental because it is known to be associated 